\title{
Anal adenocarcinoma: case report, literature review and comparative survival analysis
}

\author{
Cynthia J Tsay, ${ }^{1,2}$ Thomas Pointer, $^{3}$ Jocelyn B Chandler, ${ }^{4,5}$ Anil B Nagar, ${ }^{1,2}$ \\ Petr Protiva (D) 1,2
}

To cite: Tsay CJ, Pointer T, Chandler JB, et al. Anal adenocarcinoma: case report, literature review and comparative survival analysis. BMJ Open Gastro 2021;8:e000661. doi:10.1136/ bmjgast-2021-000661

- Additional supplemental material is published online only. To view, please visit the journal online (http://dx.doi. org/10.1136/bmjgast-2021000661).

Received 24 March 2021 Accepted 11 May 2021

Check for updates

(C) Author(s) (or their employer(s)) 2021. Re-use permitted under CC BY-NC. No commercial re-use. See rights and permissions. Published by BMJ.

${ }^{1}$ Medicine, Section of Digestive Diseases, Yale University School of Medicine, New Haven, Connecticut, USA

${ }^{2}$ Medicine, VA Connecticut Healthcare System-West Haven Campus, West Haven, Connecticut, USA

${ }^{3}$ Yale University Undergraduate Program, New Haven,

Connecticut, USA

${ }^{4}$ Pathology, Yale School of Medicine, New Haven, Connecticut, USA

${ }^{5}$ Pathology, VA Connecticut Healthcare System-West Haven Campus, West Haven, Connecticut, USA

Correspondence to Dr Petr Protiva; petr.protiva@yale.edu

\section{ABSTRACT \\ Introduction Anal adenocarcinoma is a rare malignancy with a poor prognosis.}

Methods We present a case of rare anal adenocarcinoma in a patient with normal screening colonoscopy. Using the Surveillance, Epidemiology and End Result database between 2000 and 2016, we performed survival analysis among individuals $>20$ years old comparing anal and rectal cancers.

Results Survival analysis showed that anal adenocarcinoma is associated with worse outcomes compared with rectal adenocarcinoma and anal squamous cell carcinoma.

Discussion This case and survival data illustrate the importance of prompt investigation of symptoms irrespective of colorectal cancer screening status with careful attention to examination of the anal area.

\section{INTRODUCTION}

Primary adenocarcinoma of the anus is a rare disease accounting for only $5 \%-10 \%$ of anal canal malignancies compared with the anal squamous cell carcinoma accounting for $85 \% .^{1}$ Approximately $0.2 \%$ of men and women will be diagnosed with anal cancer at some point during their lifetime, based on 2016-2018 US data. We aim to present a clinical case report of anal adenocarcinoma, provide a review of the pertinent literature, and perform a comparative survival analysis of anal neoplasms.

\section{CLINICAL CASE PRESENTATION}

We report the case of a 70-year-old man with a medical history of seropositive rheumatoid arthritis, anaemia, hypertension, hyperlipidaemia, gastro-oesophageal reflux disease, and lung nodules who was admitted for scrotal swelling and erythema thought to be cellulitis. Given no improvement with antibiotics, dermatology was consulted. The exam was notable for penile/scrotal lymphedema with elephantiasis nostras verrucosa and a firm perianal nodule, with several adjacent papules, thought to be an inflamed external hemorrhoid. The patient reported noticing a lump near the anus 1 month prior to presentation. He also described serosanguineous anal drainage for multiple years, but no haematochezia or melena, which he had attributed to internal haemorrhoids. His screening colonoscopy 5 years prior had demonstrated findings of diverticulosis and internal haemorrhoids with no anorectal lesion documented by high resolution images. CT scan demonstrated pelvic lymphadenopathy. PET scan revealed hypermetabolic uptake at the rectum extending to the anal verge, gluteal fold, posterior scrotal sac, lymphadenopathy in the abdomen and pelvis from the iliac chain to external femoral nodes, and a hepatic lesion suspicious for metastatic disease.

A shave perianal biopsy was performed. Immunohistological stains were positive for CK7 and negative for CK20, CDX2, SOX-10 consistent with adenocarcinoma. The patient underwent repeat colonoscopy and the local exam revealed a large mass outside the rectum arising from anus which was palpable on digital rectal exam. An ulcerated anal mass invading the squamocolumnar junction of the anorectal area was seen on retroflexion (figure 1, top part). Biopsy of the lesion obtained during colonoscopy demonstrated invasive moderately to poorly differentiated anal adenocarcinoma with an unusual immunohistochemistry pattern for rectal cancer (weakly positive CK7 and negative CK20, figure 1, middle part). The initial treatment plan was aggressive cytoreduction with induction chemoradiation and surgery; however, surgical evaluation was delayed given the patient's reluctance for anorectal resection. After further review of pathology and given the intra-abdominal lymphadenopathy in the staging PET scan, the tumour board 


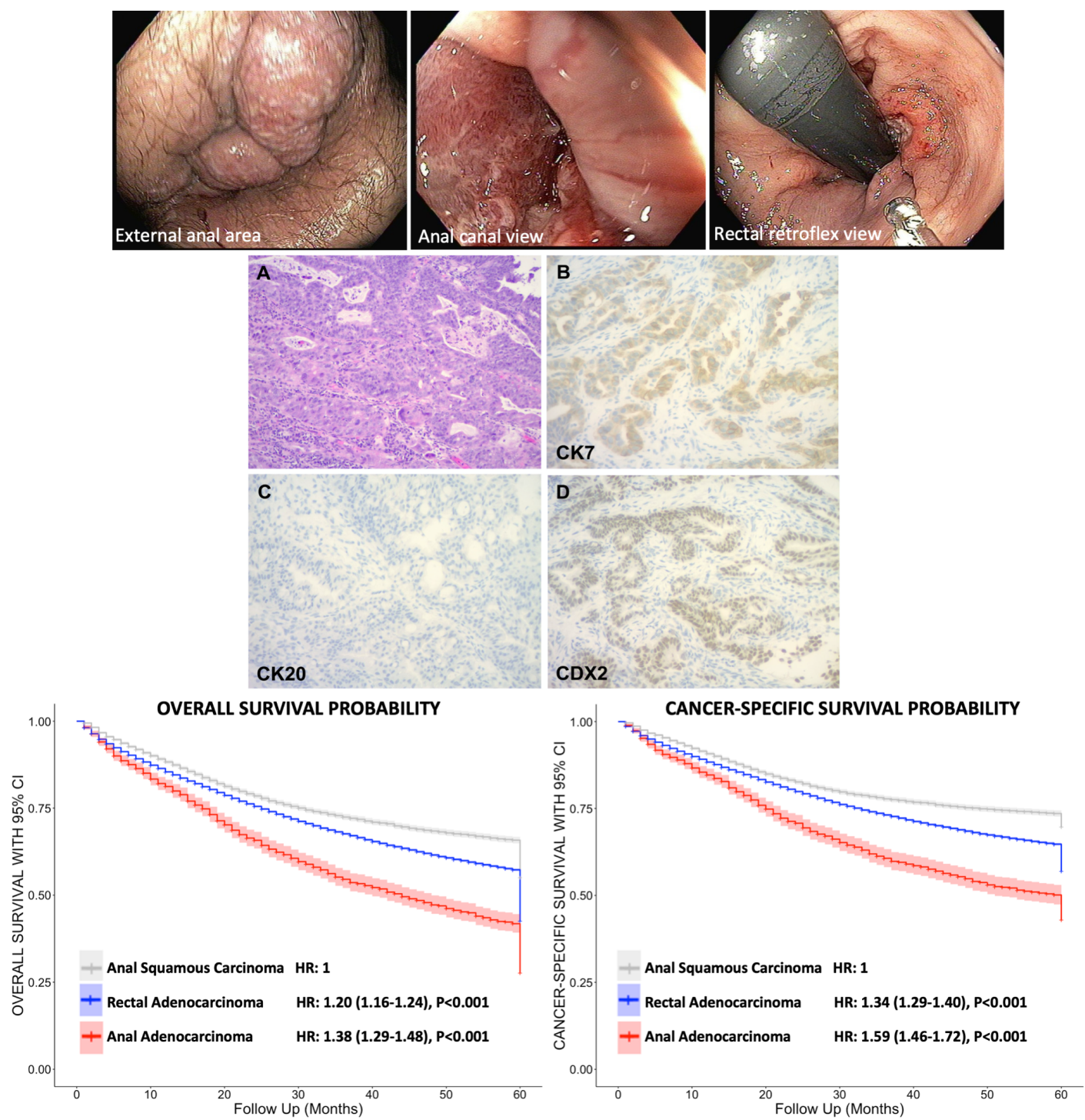

Figure 1 Top part: colonoscopy showed large anal mass with extension above the anorectal junction. Patient had previous screening exam 5 years prior to diagnosis with documented normal anorectal junction on high-resolution endoscopic photography. Middle part: histology, (A) cribriform and glandular architecture (H\&E, 100x); (B) weakly positive CD7 stain (200x); (C) negative stain for CD20 (200x) and (D) positive stain for CDX2 (200x). Bottom part: overall and cancer-specific survival experience for the three types of cancer. The adjusted HR and P values are shown directly in the figure. The anal adenocarcinoma shows the worst prognosis.

recommended treatment of the lesion as a rectal adenocarcinoma with extension into the perianal skin rather than as an anal adenocarcinoma. Subsequent tumour profiling demonstrated a high microsatelliteinstability and was KRAS/NRAS/BRAF wild type. Definitive chemoradiation was planned, pending response to induction therapy. Surgical interventions, including resection and a diverting colostomy, were deferred given lack of stool incontinence. Palliative care was consulted for support throughout treatment course.

\section{CLINICAL CASE FOLLOW-UP}

Over a year after diagnosis, the patient is alive and managed with pembrolizumab. Surveillance imaging after 6 cycles of pembrolizumab demonstrated a decrease in size of some intra-abdominal lymphadenopathy suggestive of response to immunotherapy with stability on restaging scans. Prior chemotherapy regimens included modified Folinic acid"FOL", Fluorouracil "F", and Oxaliplatin which was complicated by coronary vasospasm (after 5-Fluorouracil bolus) and coronary arterial disease requiring placement of a drug eluting stent. Oxaliplatin, irinotecan, panitumumab were stopped due to diarrhoea and the development of a gluteal abscess. He also developed a DVT and remains on life-long anticoagulation. The patient's functional status remains good with an Eastern CooperativeOncology Group of 1. Given his reports of ongoing mild intermittent rectal bleeding per the oncology clinic notes, there are tentative plans for a future sigmoidoscopy. 


\section{LITERATURE REVIEW}

Risk factors for anal adenocarcinoma have not been studied widely given the small sample sizes. Nevertheless, it is thought the immunosuppression, perianal Crohn's disease, and older age may be associated with increased risk. Unlike anal squamous cell carcinoma which has been associated with the human papilloma virus, no such association with anal adenocarcinoma has been established. ${ }^{12}$ Differentiating between distal rectal adenocarcinoma with local spread and primary anal canal tumours is challenging. Anal adenocarcinoma is associated with higher mortality compared with rectal adenocarcinoma or anal squamous carcinoma. ${ }^{3}$ A recent classification suggests that anal adenocarcinomas can be subdivided into two types: (1) colorectal from mucosa above the dentate line and (2) extramucosal from anorectal fistulae or anal glands. Given challenges with classification and the low number of overall cases, most of the literature is limited to case reports or observational studies focused on management and outcomes; often times in comparison or together with the more prevalent anal squamous cell carcinoma or rectal adenocarcinoma. Historically, anal adenocarcinoma was treated like rectal cancers with abdominoperineal resection. A follow-up study recommended that chemoradiation provided comparable outcomes and that abdominoperineal resection be used as salvage therapy. A large database study looking at survival outcomes of anal adenocarcinoma noted that a shift in the treatment paradigm to neoadjuvant chemoradiation followed by surgery, similar to management of rectal cancer. ${ }^{4}$ Recent larger administrative database studies and a systematic review have confirmed that a multimodal approach for anal adenocarcinoma incorporating surgery with chemoradiation rather than chemoradiation alone leads to improved overall survival, with highest median survival noted after neoadjuvant chemoradiation. $^{25-7}$

\section{METHODS}

We used the Surveillance, Epidemiology and End Result (SEER18) database to identify patients with anal or rectal malignant neoplasms aged 20 years or older between 2000 and 2016. The SEER database includes data from 18 population-based registries covering approximately $26 \%$ of US patients with cancer. We used a combination ICD10 (C20.9, C21.0 and C21.1) and ICD-O-3 histological codes to identify cases of anal adenocarcinoma, rectal adenocarcinoma and anal squamous carcinoma. We excluded cases where the data on stage, grade, histology were missing and cases with more than one primary malignancy. We used the SEERStat software (V.8.1.5) to collect covariates including age at diagnosis, year of diagnosis, sex, race, primary cancer site, tumour stage and grade, survival in months, cause of death, marital status, surgery, chemotherapy and radiation treatments.

We compared survival using the Mantel-Haenszel LogRank Test. Relative HRs for death in the 5-year period following diagnosis were estimated with Cox proportional hazards. The independent effect of cancer type was assessed using a Cox model adjusted for covariates identified above. Data were analysed using SAS V.9.4 and $\mathrm{R}$. The $\mathrm{p}$ value for significance was set at $<0.01$ for a twosided test.

\section{SURVIVAL ANALYSIS}

We identified a total of 93706 cases: 1660 cases of histologically confirmed anal adenocarcinoma, 12591 cases of anal squamous carcinoma, and 79455 cases of rectal adenocarcinoma with complete set of covariates. Online supplemental table 1 shows descriptive statistics for the cohort by type of malignancy.

Next, we analysed and compared survival by tumour type. Anal squamous carcinoma exhibited the best overall and cancer-specific survival compared with both anal and rectal adenocarcinomas $(p<0.001)$ (figure 1). Anal adenocarcinoma had a significantly worse survival when compared with anal squamous and rectal neoplasms $(\mathrm{p}<0.001)$. The adjusted HRs by the type of neoplasm are shown directly (figure 1); the complete result of the multivariate Cox regression analysis for independent effect of the three types of anorectal cancers are presented in the online supplemental tables 2,3. Several other covariates were also associated with survival. Not surprisingly, advanced stage and grade, and the absence of surgical, radiation or chemotherapy interventions were associated with worse survival experience $(\mathrm{p}<0.001)$. In addition, male sex, year of diagnosis, age $\geq 55$ years, unmaried status and persons identifying as black or American Indian/ Alaska Native were also associated with significantly worse survival $(p<0.001)$. Full list of covariates with associated HRs are detailed in online supplemental tables 2,3.

\section{DISCUSSION}

This case highlights the challenges of early diagnosis of anal malignancies and the importance of prompt evaluation of anorectal area by anoscopy and colonoscopy if symptoms of rectal bleeding or serosanguinous anal discharge are reported. The lesion presented as an anal neoplasm in a patient with a documented normal anorectal junction on screening colonoscopy 5 years prior. The anal malignancy was poorly differentiated and the possibility of low rectal adenocarcinoma with large extension into the perianal skin rather than primary anal adenocarcinoma is not entirely excluded. This case illustrates the difficulties in diagnosis of poorly differentiated anal carcinomas extending to the rectum. The lesion likely developed in the interim; therefore, the colonoscopy result was probably not a false negative. Anal cancers can be detected during routine screening colonoscopy of asymptomatic patients. However, new symptoms such as rectal bleeding or serosanguinous anal discharge should prompt careful rectal and anal examination. This should include patients who are up to date on their colorectal cancer screening. 
Survival analysis showed that anal adenocarcinomas exhibit the worst prognosis. Using the National Cancer Database research, others have previosuly shown that anal adenoracinoma carries poor prognosis. ${ }^{3}$ We used a similar approach using the SEER database and analysed a larger set of anal adenocarcinomas cases and additional covariates such as ethnic backround, marital status, year of diagnosis and the type of treatment. The SEER database is associated with incomplete entries and self-reported data such as ethnic background and race. The precision of adjusted hazards for some individual covariates could be limited due to small sample size. However, large number of cases with complete set of covariates allowed adequate precision of hazard estimates for the independent effect of cancer type on survival.

Contributors Guarantor of the article: PP, MD MPH, accepts official responsibility for the overall conduct of this study and publication of this manuscript. Study conception and design: CJT, TP, ABN, PP. Data acquisition: CJT, PP. Analysis and interpretation of data: all authors. Drafting of the manuscript: CJT, PP. Critical revision of the manuscript for important intellectual content: all authors. Final manuscript approval: all authors.

Funding The authors have not declared a specific grant for this research from any funding agency in the public, commercial or not-for-profit sectors.

Competing interests None declared.

Patient consent for publication Not required.

Provenance and peer review Not commissioned; externally peer reviewed.

Data availability statement Survival data are available in a public, open access repository. publicly available database.

Supplemental material This content has been supplied by the author(s). It has not been vetted by BMJ Publishing Group Limited (BMJ) and may not have been peer-reviewed. Any opinions or recommendations discussed are solely those of the author(s) and are not endorsed by BMJ. BMJ disclaims all liability and responsibility arising from any reliance placed on the content. Where the content includes any translated material, BMJ does not warrant the accuracy and reliability of the translations (including but not limited to local regulations, clinical guidelines, terminology, drug names and drug dosages), and is not responsible for any error and/or omissions arising from translation and adaptation or otherwise.

Open access This is an open access article distributed in accordance with the Creative Commons Attribution Non Commercial (CC BY-NC 4.0) license, which permits others to distribute, remix, adapt, build upon this work non-commercially, and license their derivative works on different terms, provided the original work is properly cited, appropriate credit is given, any changes made indicated, and the use is non-commercial. See: http://creativecommons.org/licenses/by-nc/4.0/.

ORCID iD

Petr Protiva http://orcid.org/0000-0002-5566-8820

\section{REFERENCES}

1 Nelson RA, Levine AM, Bernstein L, et al. Changing patterns of anal canal carcinoma in the United States. J Clin Oncol 2013;31:1569-75.

2 Anwar S, Welbourn H, Hill J, et al. Adenocarcinoma of the anal canal a systematic review. Colorectal Dis 2013;15:1481-8.

3 Franklin RA, Giri S, Valasareddy P, et al. Comparative survival of patients with anal adenocarcinoma, squamous cell carcinoma of the anus, and rectal adenocarcinoma. Clin Colorectal Cancer 2016;15:47-53.

4 Malakhov N, Kavi AM, Lee A, et al. Patterns of care and comparison of outcomes between primary anal squamous cell carcinoma and anal adenocarcinoma. Dis Colon Rectum 2019;62:1448-57.

5 Lewis GD, Haque W, Butler EB, et al. Survival outcomes and patterns of management for anal adenocarcinoma. Ann Surg Oncol 2019;26:1351-7.

6 Wegner RE, White RJ, Hasan S, et al. Anal adenocarcinoma: treatment outcomes and trends in a rare disease entity. Cancer Med 2019:8:3855-63.

7 Li R, Shinde A, Fakih M, et al. Impact of surgical resection on survival outcomes after chemoradiotherapy in anal adenocarcinoma. $J$ Natl Compr Canc Netw 2019;17:1203-10. 